\title{
The factor and application strategy of connotation development in industry characteristic university
}

\author{
Huang Haochen ${ }^{1, a}$,Ping fangfang ${ }^{2, b}$ \\ ${ }^{1}$ Section of Strategic Planning and Laws Regulation, Wuhan University of Technology, Wuhan \\ 430070, China; \\ ${ }^{2}$ Department of Propaganda, Wuhan Radio and Television Station, Wuhan 430070, China. \\ a1020700752@qq.com, b553928672@qq.com
}

Keywords: Industry ;characteristic; culture; connotation

\begin{abstract}
The connotation in the industry characteristic university mainly include four factors which are safeguard factor, promotion factor, brand building factor and cultural factor. It is necessary to clarify the logical relation, function mechanism and operation mode of developmental factors in industry characteristic universities. The effective applies strategies include consolidating the safeguard, establishing development goals, enhance the core competition, and guide the value orientation of the industry.
\end{abstract}

\section{Introduction}

Compared with the ordinary university, industry characteristic university has the mature natural advantage. The construction of characteristics subjects have a high starting point. There is a mature resource sharing platform.

It is easy to form the integration of industry characteristics and social value of the development culture. At present, the society need the innovative talents. We need to integrate the elements of development by the university's culture. We need to analyze the industry characteristic university's connotation development elements.

\section{The basic structure of the connotation development in the characteristics university}

The industry characteristics university developed in the long-term practice. These university are concentrated on the long-term service in the industry development. The development of industry characteristic universities is subject to influence the economic and social development.

The most important thing is how to coordinate the relationship of resource and quality. Any part which is imbalance will cause trouble. It lies in the relationship between the coordination of resources. In terms of its development model, two external factors are essential. External part contain power and resources. Internal part contain utilization and conversion. And both part are indispensable.

It is necessary to achieve the best results with good relationship between the two parts. The factors are the driving force and resources. The component elements include infrastructure protection, scientific orientation, education idea, system design, teachers and so on. They are interrelated in the development of industry characteristic universities.

According to the logic standards from the surface to the core. It can be divided into four elements which are safeguard factor, promotion factor, brand building factor and cultural factor. The structure is shown in figure 1. 


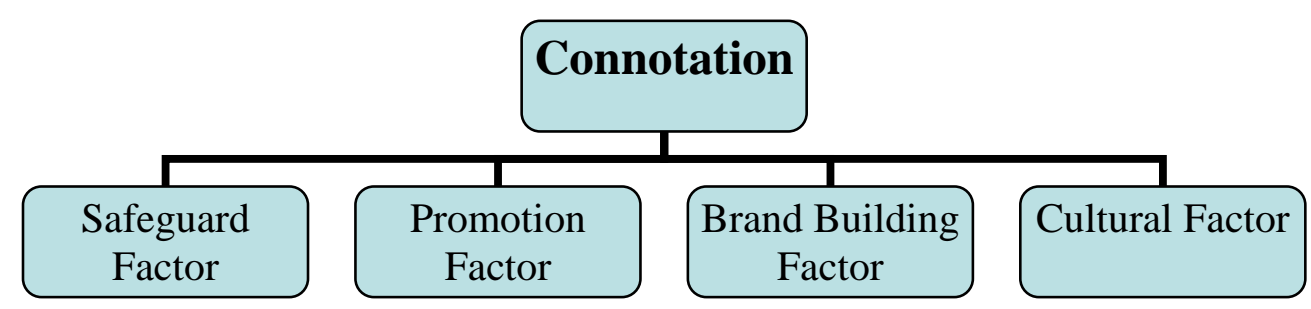

Figure 1. The structure of the connotation development

The safeguard factor is to maintain the normal operation of the University. It mainly includes the talent cultivation, layout of disciplines, teaching and research, social services and international exchanges and cooperation. These elements can reflect the existence of university internal demand and development. It can reflect the urgent requirement of service economy society. Promotion factor can highlight the uniqueness and replace ability of college. It include public evaluation, social influence and other immateriality factors. The brand building factor contain propaganda strategy, public evaluation and social influence. The cultural factor can best embody the university's value and social function. It contain the spirit of the campus. These elements are organic unity which constitute a complete system in the industry characteristic university connotation development.

\section{The interactive relationship with the connotation development factors}

The above four factors not only forms the basic development process of the connotation development of the industry characteristic university, but also optimize the cross layer interaction between the elements.

The industry characteristic university must carry on the top design from the internal operation mechanism. It should have an idea to solve the "what to do" and "how to run" the colleges. Compared with the general public universities, the development orientation of the industry characteristic university is more emphasis on the characteristic. The existing advantages and the development goal of the school is important. The key is to link the development strategy of the University of industry characteristics. We must have a top-level design and characteristic position. The characteristics should contain industry characteristics and school's characteristics.

In the process of the basic development process, the intrinsic value of the industry characteristic university has been realized. The elements is gradually divided into two trends which are internal and external parts. There is a basic development cycle mechanism in the formation of industry characteristic universities. Each factor interact with each other. On the other hand, it should meet the actual needs of the market and carry out competition based on its own development logic.

With the continuous improvement of the institutional mechanisms. Management innovation will eventually contribute to the overall construction of the industry characteristic university cultures. In a certain period to form a complete operation process. these elements are interdependent and support each other. So the industry characteristics University connotation development should be the coordinated development of the four elements. Their interaction and continuous operation form the basic operation mode of the development of the school connotation.

\section{The strategy to use the connotation development elements}

We just understand the connotation development elements is not enough. We need to know how to use them. A good grasp of the relationship between these factors is necessary.

\subsection{Consolidate the basis safeguard, establish development goals}

Characteristic universities should clearly identify their own development goals. It should recognize their position in the higher education market.

characteristic college should first research the goal. What are the needs of the characteristic school. What are the needs of the society. The overall design is the important part for the university to get the connotation development. At present, university education in our country is seriously. some industry characteristic universities are facing the problem of "losing essence". The key to the 
development of the strategic objectives is to find their own position. Characteristic development orientation is to optimize the allocation of resources to the University. China's industry characteristics of the university should priority solve the problem what are the development and positioning of good characteristics.

\subsection{Pay attention to the quality of development and collaborative innovation}

The current national driven strategy provides a broad space for the development of the connotation. Universities should be based on the development of service industry's needs. It should explore a win-win cooperation model. The connotation development of industry characteristic university must put he talent cultivation to its basic task. Higher education is the engine to the regional development.

We can learn the best practices of famous universities around the world. For example, The United States is one of the most developed country in higher education. The development of silicon valley is successful. The university of Stanford's science and technology industrial park is the first university's high-tech industrial park in United States. Practice proves that it is successful. The combination of technology and regional economy is close through the establishment of science and technology industrial park.

\subsection{Enhance core competitiveness and create a brand}

The university's brand is composed of a general evaluation and impression of the public's attitude. But some characteristic university just pursuit of wide area development in a certain field. Under the background of education popularization, the industry contribution value is weakened in characteristic universities. Therefore, the urgent need to reflect the latest development direction in characteristics. In recent years, Wuhan University of science and technology give a priority to the development of materials, engineering, civil engineering and other first-class disciplines. The brand of industry characteristic universities has been created to satisfy the society's need. It format a core competitiveness in some subject.

\subsection{Bring up the culture and guide the industry's value orientation}

The university's culture mode cannot be formatted in a short time. It is made of tangible and intangible resources. The education's process is providing high quality educational services to the society. In essence, it is also the process of cultural inheritance and innovation. We called it a "soft power". It's a unique cultural character in the college. The university's cultural construction is not a easy work. The industry characteristic universities should integrate its own resources. It should focus on the main role in social practice.

Wuhan University of Science and Technology has been practicing the "outstanding talent" values in recent years. The "excellence in the creation of life" is the core of the campus culture. Every student guide their practice under the culture. It gradually format a common value orientation to the industry of material and car. There is a common spirit to lead the industry culture by these method.

\section{Summary}

In these paper we analyze the connotation development of industry characteristic university from the angle of the constituent elements. Because the unique development advantages and specific service oriented. It should grasp the essential link between the four factors. They are safeguard factor, promotion factor, brand building factor and cultural factor. In practical way, it should keep existing advantages and industry resources. The college can cultivate a large number of innovative talent in the industry. It is necessary to enhance the capacity to service industry development and regional economic and social development. Finally it can form a innovation. The culture of the industries should develop gradually.

\section{References}

[1] Arocena, R., \& Sutz, J. (2005). Latin American universities: From an original revolution to an uncertain transition. Higher Education,50, 573-592. 
[2] Geuna, A. (1999). The economics of knowledge production. Funding and the structure of university research. Cheltenham: Edward Elgar.

[3] Alf Lizzio\& Keithia Wilson. Active Learning in Higher Education: an investigation of its potential to develop professional capability [J].Studies in Higher Education vol8 (2004) .

[4] Dependence on External Finance: An Inherent Industry Characteristic. George M. Von Furstenberg, Von Kalckreuth in Open Economies Review(2006)

[5] P. D Este, P. Patel.University-industry linkages in the UK: What are the factors underlying the variety of interactions with industry? Volume 36, Issue 9, November 2007, Pages 1295-1313

[6] Gordon M. Bodnar,William M. Gentry.Exchange rate exposure and industry characteristics: evidence from Canada, Japan, and the USA. Journal of International Money and Finance.Volume 12, Issue 1, February 1993, Pages 29-45 